\title{
Guidance on the Stand Down, Mothball, and Reactivation of Ground Test Facilities
}

\author{
Gregrey T Volkman ${ }^{\mathrm{a}}$ \\ Jacobs Technology, Inc., ROME Group, Hampton, VA, 23681 \\ Steven C. Dunn ${ }^{\mathrm{b}}$ \\ Jacobs Technology, Inc., ROME Group, Hampton, VA, 23681
}

\begin{abstract}
The development of aerospace and aeronautics products typically requires three distinct types of testing resources across research, development, test, and evaluation: experimental ground testing, computational "testing" and development, and flight testing. Over the last twenty plus years, computational methods have replaced some physical experiments and this trend is continuing. The result is decreased utilization of ground test capabilities and, along with market forces, industry consolidation, and other factors, has resulted in the stand down and oftentimes closure of many ground test facilities. Ground test capabilities are (and very likely will continue to be for many years) required to verify computational results and to provide information for regimes where computational methods remain immature. Ground test capabilities are very costly to build and to maintain, so once constructed and operational it may be desirable to retain access to those capabilities even if not currently needed. One means of doing this while reducing ongoing sustainment costs is to stand down the facility into a "mothball" status - keeping it alive to bring it back when needed. Both NASA and the US Department of Defense have policies to accomplish the mothball of a facility, but with little detail. This paper offers a generic process to follow that can be tailored based on the needs of the owner and the applicable facility
\end{abstract}

\section{Introduction}

$\mathrm{T}$ HIS document provides guidance for developing plans and procedures for deactivating, maintaining, and reactivating ground test facilities and systems in accordance with the definition of Mothballed status in NASA Procedural Requirement (NPR) 8800.15B, Chapter $5^{1}$ and Department of Defense Instruction, Number 3200.18, Appendix 3 and Appendix $4^{2}$.

The following, an excerpt from NPR $8800.15 \mathrm{~B}$, provides context for mothballed status:

"A facility is classified as "Active" if it is being utilized for a specific current program, near-term program, or institutional requirement. A facility that does not have a specific current or near-term program or institutional requirement is classified as "Inactive." Inactive facilities or parts of facilities are classified by status: Abandoned, Mothballed, or Standby. The following conditions characterize all inactive facilities or parts of facilities that are inactive:

1. No personnel occupy the facility.

2. Utilities are curtailed, other than as required for fire prevention, security, or safety.

3. The facility is secured to prevent unauthorized access and injury to personnel.

4. The facility does not receive funding for renewal or other significant improvement.

\footnotetext{
a Mechanical Engineering Supervisor (and Mothball Plan project manager), ROME Group, NASA Langley Research Center, Mail Stop 440, Hampton, VA, 23581.

${ }^{\mathrm{b}}$ Chief Engineer, ROME Group, NASA Langley Research Center, Mail Stop 267, Hampton, VA, 23681, Senior Member.
} 
"Abandoned" status applies to inactive facilities for which there are no reactivation plans.

Facility systems and collateral equipment will be considered for excess or identified for use at other NASA locations where it is feasible and cost effective.

"Mothballed" status applies to facilities that have been deactivated, but maintenance measures have been taken to prevent deterioration of essential systems. Mothballing generally results in higher first-year costs, but future annual costs are lower due to reduced maintenance and repair requirements. The total time to deactivate and then to reactivate a facility, including the mothballed period, generally exceeds 36 months. In addition to the conditions indicated above, the following conditions characterize mothballed facilities:

1. Utility systems and collateral equipment have been properly prepared for long-term inactivation without significant deterioration. Selected systems, such as cathodic and fire detection systems are kept in operation and routinely inspected.

2. The facility interior is equipped with appropriate environmental control to prevent significant deterioration.

3. Hazardous materials have been removed.

4. The facility exterior envelope is inspected routinely and the integrity and appearance of the exterior shell are maintained.

5. Personal property is reported to the Center Personal Property Office for reutilization.

"Standby" status applies to facilities that are temporarily not in use but appropriate maintenance measures have been taken to maintain essential operating systems in a state of readiness or availability for future use. Selective, costeffective facilities maintenance and repair are required. Total time to deactivate and then to reactivate the facility, including the standby period, is expected to be 36 months or less."

The decision to mothball a facility results from an assessment of the current to longer term situation (current and projected workload and mission alignment, sustainment costs, and facility condition). For a decision to mothball, presumably current mission alignment is low but longer term ( $>3$ years) is potentially much higher. The cost to mothball a facility - while typically lower than the cost to sustain it in active service - is still significant, so the potential future need must be of sufficient importance and likelihood to justify the mothball cost. The "life cycle" of mothballing a facility is essentially three phases: deactivation, inactive/mothball, and reactivation. The scope, time, and costs for each phase are a trade-off with the other phases. If the desire is to minimize current and near-term costs, that can be done with the trade of more scope, time, and cost to reactivate.

An extreme situation, which has happened repeatedly in the ground test environment, is to abandon a facility only to begin to or actually reactivate it later. The reactivation costs of this scenario are much higher due to lack of proper preservation of existing equipment and documentation, lack of equipment and information organization, little to no attention to knowledge capture, and replacement of equipment that was initially salvaged and used elsewhere.

The guidelines, recommendations, and philosophies outlined in this document were taken directly from practices and processes cited in references 1 - 14 and from typical facility site visit observations and assessment. This content can be used to assist personnel responsible for developing a Facility Mothball Plan for a respective facility. This document addresses the general format of a Mothball Plan; stabilizing and assessing the condition of the facility; notifications and documentation required; the Fire, Life Safety, and Environmental Requirements; and general guidelines for preparing, maintaining, and reactivating the facility structure, systems, and equipment. The information was initially developed for use at any NASA Center, but it is suggested that its fundamental nature will allow it to be a reference for any ground test facility under consideration for mothballing.

The scope of this document is limited to discussing general guidelines, recommendations, and philosophies for the development of a Facility Mothball Plan; however, additional facility specific requirements must be considered and included. Additionally, all of the recommended documentation and a location to archive and maintain the Plan and documentation should be defined as the Plan is being developed. 


\section{Work Scope Trade-Offs Between Deactivation, Mothball State, and Reactivation}

A ground test facility typically is complex with a high (tens of millions of dollars or more) replacement value. Sustaining a high value facility is expensive, in the range of $2-4 \%$ annually of current replacement value ${ }^{15}$ plus investment for upgrades and recapitalization. An owner, especially when trying to spread limited maintenance funding across multiple facilities may look to stand down a low use or currently unused facility to focus funds on currently higher need facilities. The preparation for mothballing a facility combined with reduced annual maintenance still comes with a significant cost, so the owner must trade off how much work (and cost) to invest during preparation for mothball and how much maintenance to accomplish annually against the time and cost of reactivating the facility in the future. The mothball duration also factors in, as the longer the facility is down, the more effort it will take to bring back.

It is recommended that the owner accomplish a trade study using the elements in this paper plus unique features of the facility that must be addressed. The trade is to define how much work is accomplished during deactivation and while the facility is down against the work to bring it back. Obviously, the less that is done up front and while down will drive more work to reactivate. The study should make an economic assessment, based on system by system cost estimates for a range of work - perhaps the choices could be do nothing, minimum to 'keep it alive', and desired level. The deactivation work and maintenance while down will vary by system type, current condition, and criticality to operation. Additionally, there are certain minimum sustainment costs that will have to be borne as long as the facility exists related to safety and security. Some additional considerations are:

- Facility condition entering the deactivation correlates with reactivation scope. If the facility is in degraded condition to begin with, more work will be required to later return it to service.

- The facility does not necessarily have to be brought back to full service. It is the owner's prerogative to either plan up front or at reactivation to return only a portion of the capabilities to service.

- The longer the downtime duration, the more expensive and difficult it will be to return to service.

- Equipment degrades over time and sometimes becomes obsolete.

- Facility subject matter experts will become more dispersed and their knowledge and records harder to retrieve.

- Pressure will likely increase over time on owners to reduce ongoing maintenance on a mothballed facility, driving up potential reactivation scope.

- Technology growth over time will tend to make mothballed facility capabilities obsolete.

- During the trade study, it is recommended to identify the most critical (and, probably highest value) systems/equipment and focus limited funds on preserving these.

\section{Elements of a Mothball Plan}

The mothball plan is included as Appendix 1 and is organized by the major facility mothball life cycle phases: preparation and plan development, deactivation, facility mothballed, and reactivation (return to service). The high level work breakdown is shown below:

I. Facility Mothball Plan Development

A. Facility Mothball Plan Format and Documentation

B. Facility Mothball Plan Review and Approval

II. Deactivation of a Facility

A. Fire and Life Safety

B. Environmental

C. Building Structure

D. Plumbing Systems and Equipment

E. Mechanical Systems and Equipment

F. Electrical

G. Communication Systems

H. Data Acquisition Systems (DAS) and Facility Automation Systems (FAS)

I. Food Service Equipment and Storage

J. Office Furnishings 
III. Preservation and Maintenance During Mothball Status
A. Fire and Life Safety
B. Environmental
C. Building Structure
D. Plumbing Systems and Equipment
E. Mechanical Systems and Equipment
F. Electrical
G. Communications
H. Data Acquisition Systems (DAS) and Facility Automation Systems (FAS)

IV. Reactivation of a Facility
A. Fire and Life Safety
B. Environmental
C. Building Structure
D. Plumbing Systems and Equipment
E. Mechanical Systems and Equipment
F. Electrical
G. Communication Systems
H. Data Acquisition Systems (DAS) and Facility Automation Systems (FAS)

\section{Conclusion}

This paper was created to document a generic mothball process developed at NASA Langley Research Center and share the material with the aerospace/aeronautics ground test community. The content is based on industry practices and observations of a facility case study to define actions to mothball that facility. The content is generic and can be a starting list of considerations to mothball a facility - it is very likely for specific applications that some content won't apply and facility peculiar content will need to be added.

The process at its core is a trade study of defining what to accomplish during deactivation and when mothballed against the cost and time for reactivation. The cost to properly stand down a facility can be daunting to an owner that is standing the facility down to save budget; it is important to identify the most critical components (operationally and from a business case perspective) and at least address those. The starting condition of the facility (including physical/technical condition, knowledge capture, and staff breadth) is also a major factor in determining reactivation needs. It is likely that the longer the duration of the mothball period, the larger the "bow wave" will grow for reactivation scope; at some point it may not be economically viable to bring it back.

The mothball process is one method to sustain a capability in a time of lean workload and/or budgets. It can be an expensive process, but is probably at least an order of magnitude less than the cost of building a new facility for a future need. The process also allows the return of partial capability to meet a particular need. It is hoped that this document provides some useful guidance to facility owners faced with the need to stand down a facility.

\section{Acknowledgments}

The core of this paper was originally generated as a work product by a Jacobs Technology, Inc., ROME Group, project team in coordination with the NASA Langley Research Center, Center Operations Directorate (COD). The bulk of the work to assemble the elements of the mothball plan was accomplished by the project team and reviewers and the authors especially wish to thank Mr. Bradford Clements, Mr. Gary Wilson, Mr. Jack Menke and Mr. Mark Rollins. Overall management and coordination on specific content was accomplished by the NASA COD project manager, Mr. Michael Harrell. The authors wish to thank Mr. Harrell both for his contribution to this work and also for permission to publish the report as an AIAA paper.

The original paper was written as an internal document, so specific reference citations were not noted. Much of the material was taken directly from cited sources and was not coordinated with source authors; thus, any errors or omissions of material taken from those sources are the responsibility of the paper authors. 


\section{References}

${ }^{1}$ NASA Procedural Requirement 8800.15B, “Real Estate Management Program”, Chapter 5, “Facilities Utilization”, 6/21/10.

${ }^{2}$ Department of Defense Instruction, Number 3200.18, "Management and Operation of the Major Range and Test Facility Base", Appendix 3, "Procedures for requesting an MRTFB Facility or Range to be Placed in a Mothballed Status", and Appendix 4, "Procedures for Requesting the Reinstatement of an MRTFB Facility or Range from a Mothballed Status to an Active Status", February 1, 2010.

${ }^{3}$ Management of Inactive Facilities, NASA Langley Policy Directive 8800.16, 1/4/2012.

4،"How to Protect Your Boiler During Shutdowns”, NALCO Chemical Company, Technifax TF-23, 1997.

5“Protection of Idle Equipment “, API Guide for Inspection of Refinery Equipment, Chapter XVIII. Third Edition, April 1982.

6“Facility Closure Checklist”, NASA Langley Form 124, May 2012.

${ }^{7}$ Thomas, Scott R., Lee, Jinho, Stephens, John W., Hostler, Robert W., and Von Kamp, William D., "The Mothball, Sustainment, and Proposed Reactivation of the Hypersonic Tunnel Facility (HTF) at NASA Glenn Research Center" Plum Brook Station", AIAA 2010-4533.

${ }^{8}$ Twigg, R. J., "Guidelines for the Mothballing of Process Plants", Materials Technology Institute of the Chemical Process Industries, Inc., MTI Publication No 34, $3^{\text {rd }}$ printing, 2002.

${ }^{9}$ Price, Bernie, "Mothballing Requires More Than Idle Thought - Proper steps can protect plant assets and enhance eventual reactivation or sale", Chemical Processing, 7/8/10.

${ }^{10}$ Directorate of Public Works, "Fort Monroe Mothballing Plan”, United States Army, Fort Monroe, VA, May 2011

${ }^{11}$ Scott, Paul, "Asset Preservation - Mothball and Lay-up”, DoD Corrosion Conference proceedings, Washington, D.C., August 2009.

${ }^{12}$ Miksic, Boris A., "The Mothballing Handbook, A Corrosion Protection Guide - VpCI Solutions for Preservation, Layup and Mothballing”, Cortec Corporation, May 2006.

${ }^{13}$ Yorktown Layup Philosophy, unpublished working document from Yorktown refinery shutdown, Western Refining, in Jacobs/ROME project file, revised 9/3/2010.

${ }^{14}$ Haynes, D. E., "Protection of Non-Operating Centrifugal and Axial Compressors, Expanders, and Associated Systems Document", Dresser-Rand Group Inc., Document ID 003-074-001, 6/6/2011.

${ }^{15}$ National Research Council. Capabilities for the Future: An Assessment of NASA Laboratories for Basic Research. Washington, DC: The National Academies Press, 2010. 


\section{Appendix 1: Layout and Content of a Facility Mothball Plan}

\section{$\underline{\text { Contents }}$}

I. Facility Mothball Plan Development

A. Facility Mothball Plan Format and Documentation

B. Facility Mothball Plan Review and Approval

1. Facility Stabilization

2. Facility Condition Assessment

3. Facility Scheduled Maintenance

4. Corporate Knowledge and Control/Archive Facility Documentation

5. Deactivation Principles

II. Deactivation of a Facility

A. Fire and Life Safety

B. Environmental

1. Hazardous Materials

2. Landscape Maintenance

3. Animal and Pest Control

C. Building Structure

1. Exterior

2. Interior

D. Plumbing Systems and Equipment

1. General

2. Applicable Plumbing Systems

E. Mechanical Systems and Equipment

1. HVAC Systems and Equipment

2. Building HVAC Control Systems

3. Rotating Equipment

4. Piping and Vessels

F. Electrical

1. Lighting and Receptacles

2. Air Cooled Transformers and Substations

3. Oil Filled Transformers

4. Motors and Generators

5. UPS and Battery Systems

6. Fire Detection System

7. Environmental Monitoring Systems

8. Security Monitoring and Access Systems

G. Communication Systems

H. Data Acquisition Systems (DAS) and Facility Automation Systems (FAS)

I. Food Service Equipment and Storage

J. Office Furnishings

III. Preservation and Maintenance During Mothball Status

A. Fire and Life Safety

B. Environmental

1. Landscape Maintenance

2. Animal and Pest Control
C. Building Structure

1. Exterior

2. Interior

D. Plumbing Systems and Equipment

E. Mechanical Systems and Equipment

1. HVAC Systems and Equipment

2. Building Automation Control Systems

3. Rotating Equipment

4. Piping and Vessels

F. Electrical

1. Lighting and Receptacles

2. Air Cooled Transformers and Substations

3. Oil Filled Transformers

4. Motors and Generators

5. UPS and Battery Systems

6. Fire Detection System

7. Environmental Monitoring Systems

8. Security Monitoring and Access Systems

G. Communications

H. Data Acquisition Systems (DAS) and Facility Automation Systems (FAS)

IV. Reactivation of a Facility

A. Fire and Life Safety

B. Environmental

1. Landscape Maintenance

2. Animal and Pest Control

C. Building Structure

1. Exterior

2. Interior

D. Plumbing Systems and Equipment

1. General

2. Applicable Plumbing Systems

E. Mechanical Systems and Equipment

1. HVAC Systems and Equipment

2. Rotating Equipment

3. Piping and Vessels

F. Electrical

1. Lighting and Receptacles

2. Air Cooled Transformers and Substations

3. Oil Filled Transformers

4. Motors and Generators

5. UPS and Battery Systems

6. Fire Detection System

7. Environmental Monitoring Systems

8. Security Monitoring and Access Systems

G. Communication Systems

H. Data Acquisition Systems (DAS) and Facility Automation Systems (FAS) 


\section{Facility Mothball Plan Development}

The Facility Mothball Plan is defined as documentation that identifies the procedures required to deactivate, maintain, and then reactivate a facility, systems, and equipment during a period that generally exceeds 36 months.

1. Development of the Facility Mothball Plan must be compliant with applicable laws, policies, and procedures (such as rules and guidance on managing inactive facilities and facilities closure processes).

2. Any safety/hazard analysis report or document associated with the facility should be updated as appropriate and stored with facility documentation. If such information does not exist, it should be considered for development to ensure facility hazards and associated risk management are identified and retrievable during reactivation.

3. Official documentation (controlled drawings and procedures, including any approved change notices) related to the facility should be verified to be correct prior to initiating deactivation for mothball. These documents should be reviewed by personnel experienced with the system and updated as needed. Once the system is idle, the assumption must be made that reactivation procedures should be based on correct information at the time of deactivation.

4. Existing redlined configuration controlled drawings should be updated to show the current configuration of the facility. As part of the mothball process, any CCD documents that are changed should be updated.

\section{A. Facility Mothball Plan Format and Documentation}

The Facility Mothball Plan should include an Executive Summary that describes the facility and identifies all of the affected systems and equipment; discussion of the documentation contained in the Facility Mothball Plan; any assumptions that were made concerning the deactivation of the facility; location(s) of record documents; and names and contact information for all personnel involved in the development of the Facility Mothball Plan.

In addition to the Executive Summary, three individual documents should be created for a Facility Mothball Plan:

1. Deactivation Procedure: Outlines the steps to prepare the facility, systems, and equipment for mothball status. Refer to Section II for a more detailed explanation of guidelines and recommendations to prepare a facility for Mothball status.

2. Preventive Maintenance Plan: Outlines the scheduled preventive maintenance required for the duration of the Mothball status. Refer to Section III for a more detailed explanation of guidelines and recommendations for scheduled preventive maintenance during Mothball status.

3. Reactivation Guidance: Outlines the steps to return the facility, systems, and equipment to "Active" status. Refer to Section IV for a more detailed explanation of guidelines and recommendations to reactivate a facility from Mothball status to "Active" status.

Knowledge Capture Plans will include the information necessary to ready the facility for a customer test following reactivation from a Mothballed state. This information should include drawings, procedures, instrumentation verification, etc. necessary to allow the facility to resume testing. It may also be necessary to interview and capture additional facility operations and maintenance knowledge from facility subject matter experts - the longer the downtime, the less likely it will be that they will be available during reactivations and subsequent operations. This document is in addition to the information required ready the facility for testing. Its purpose is to focus on the test equipment and conducting a test.

\section{B. Facility Mothball Plan Review and Approval}

Appropriate personnel should be notified and involved during the development of the Facility Mothball Plan, and should review the Plan to ensure systems are safely and adequately mothballed. Appropriate personnel roles may include management of these functions: fire department, safety, environmental, energy, utilities, underground utilities, lifting/cranes, standard practice engineers, projects and engineering, real property, master planner, chief architect, security, pressure systems, maintenance, utilization and scheduling, and any specific functions associated 
with the facility. The Mothball Plan will also require specific approvals, which will be defined by facility owner/senior management. ,

\section{Facility Stabilization}

Stabilization controls the long term deterioration of the building while it is unoccupied. Stabilization can include but is not limited to: structural reinforcement, weatherization, pest control, rain water management or addressing unsafe conditions. Furthermore, initial stabilization places a structure in a condition which not only prevents further deterioration, but can also allow maintenance for the duration of the inactive period. Refer to Section 3 for guidelines and recommendations related to stabilizing the facility for Mothball status.

\section{Facility Condition Assessment}

The facility owner should perform a Facility Condition Assessment (FCA) after identifying and stabilizing a structure(s) for closure. The condition assessment is designed to establish a baseline record for the "as is" conditions which are to be maintained and used for comparison during scheduled inspections. The owner should determine if an FCA is required at the start of the mothball process.

\section{Facility Scheduled Maintenance}

Mothballed status applies to facilities that have been deactivated, but maintenance measures have been taken to prevent deterioration of essential systems, which generally results in higher first-year costs, but future annual costs are lower due to reduced maintenance and repair requirements.

Preventive Maintenance (PM) should be considered for systems/components where the value to replace is greater than the cost to perform the maintenance. To do this, the maximum duration for the mothball activities needs to be established at the start of the Facility Mothball Plan development. In addition, any items that are specialized for the facility and may have long lead times or be a one of a kind need to be properly stored and maintained.

The selection of one or more protective methods for equipment in an "inactive" facility should be based on the value of the equipment, the cost of the protective measures, the nature of protection needed, and the probability of reuse of each piece of equipment. When determining the appropriate protective measures for equipment that is expected to remain idle, the most important factor, yet indeterminate, is the predicted length of idleness. The length of the idle period affects aspects of planning, since the actions taken for a two year period versus five years may be significantly different. Items that do not require any PM for reasons such as value, should be identified and documented as to how long it may sit idle and still be considered reliable.

All PM information should be tracked and documented utilizing the applicable computerized maintenance management system (CMMS). Likewise, PM items which are no longer performed should have their asset management system placed in an "inactive mode" for tracking. This allows personnel to determine exactly what is required to reactivate a facility when those assets are placed back in "active status" and outstanding PM items are noted.

Refer to Section 4 for a more detailed explanation of recommended scheduled preventive maintenance during mothball status.

\section{Corporate Knowledge and Control/Archive Facility Documentation}

There is the possibility that some or all of the current key facility personnel will be unavailable to support future facility reactivation and operations, or that the current personnel would be so far removed from facility operations that "facility systems" retraining may be required prior to reactivation and future testing; therefore, it is important to preserve this corporate knowledge by ensuring facility drawings, design documents, operating manuals and check lists, safety information, inventory lists, historical documents and information, test reports, etc. are properly archived. Any questions regarding classified material should be directed to the appropriate security official. In addition, training plans, certification(s) process, and listing of current and recently certified personnel should be documented. Knowledge Capture Plan will include defining where the documentation is to be archived. 


\section{Deactivation Principles}

1. Where appropriate, all fluids and hazardous materials should be removed from the facility prior to the deactivation being complete unless otherwise needed for PM.

2. Heating, ventilation, and air conditioning (HVAC) systems should remain operational at reduced capacity during the mothball period to maintain above freezing temperatures and limit excessive indoor humidity in an effort to minimize mold growth.

3. The plumbing and domestic water system will not be operational during the mothballed period, unless necessary to serve operational HVAC equipment.

4. Rotating equipment will be serviced in a manner which minimizes preventive maintenance requirements. Disassembly may be required for some equipment where parts and materials may take a permanent deformation from sitting idle too long.

5. Define the key equipment which needs to remain sustained during the mothball period, and then define the ancillary equipment needed to operate the key equipment.

6. Everything in the Chemical Material Tracking System (CMTS, or equal) inventory needs to be removed from the facility.

7. Storage or future use of test hardware should be defined by facility personnel.

\section{Deactivation of a Facility}

This Section outlines guidelines and recommendations for developing the documentation for the Deactivation Procedures that will be used to prepare the facility, systems, and equipment for Mothball status. All personnel indicated in Section 2.2 should review and approve the Deactivation Procedure prior to proceeding with the deactivation.

\section{A. Fire and Life Safety}

In general, sprinkler systems should be deactivated except in facilities where a fire could spread to an active structure. Direction should be obtained from the fire chief (or other similar official) on a case by case basis, during the development of the Deactivation Procedure. If the sprinkler system is deactivated, then the entire facility must be placed in a Mothball status. It is likely not permissible to deactivate a portion of the sprinkler system. In addition, personnel from the fire department (or similar) should remove fire extinguishers and self contained breathing apparatus (SCBA) from the facility.

Refer also to Section 3.6.6 for further information concerning the Fire Detection System.

\section{B. Environmental}

\section{Hazardous Materials}

Environmental management personnel should conduct a walk-through survey of each facility prior to its closure in accordance with any applicable policies and procedures. The goal is to identify any environmental hazards for personnel who enter the facility at a later date, and to document any conditions / materials that impose environmental risk. The findings from the walk-through survey should be documented in the mothball project files.

\section{Landscape Maintenance}


Vegetation around the building should be pruned back from the walls a minimum of twelve inches to allow good airflow. Overhanging dead tree limbs and branches should be removed. Ensure foliage is not in direct contact with the structure. Remove weeds from around utility areas and sidewalks. Provide fill at grade levels where necessary to eliminate accumulation of stagnant water when such water causes a hazardous or unhealthy condition, becomes a breeding area for insects, or which causes soil erosion or damage to foundation walls.

\section{Animal and Pest Control}

Remove any existing colonies or nests of insects, rodents, snakes, or other harmful pests. Remove and dispose of any accumulation of garbage or a blighting influence such as stored materials which may harbor insects, rodents, snakes, or other harmful pests. Any penetration, such as a louver, that is accessible to pests and/or animals, and is not equipped with a damper, should be covered. The covers should be removed if the equipment is operated at anytime during the mothball period. Treat damp or infected wood with insecticides or preservatives.

\section{Building Structure}

The three highest priorities for a building in Mothball status are:

1. To protect the building from sudden loss due to environmental hazards, compromised structural integrity, etc.

2. To weatherize and maintain the property to stop moisture penetration.

3. To control humidity levels inside once the building has been secured

A properly mothballed building will have a watertight roof, secured doors and windows, repaired or stabilized rot problems, painted wood, repaired masonry, and well maintained grounds. All trash and debris should be removed from inside, outside, and under the building. All buildings or structures and all parts thereof, should be maintained in a safe and sanitary condition. It is important to remember that generally when structures are mothballed they are already in a deteriorating condition and stabilization is necessary to retard further deterioration (refer to $\underline{\text { Section } 2.3}$ ).

\section{Exterior}

a. General

1. Exterior wall surfaces should be free of breaks, holes, loose or missing materials to prevent deterioration or to pose a threat to health and safety. All exterior surfaces should be repaired and protected from the elements, including but not limited to decks, platforms, and fences. Every foundation, exterior wall, roof, and all other exterior surfaces should be maintained in structurally sound and weather tight condition.

2. Potential points for water intrusion, like crawlspace openings and basement louvers or windows, should be blocked and the water diverted away from the building; however, basement and crawlspace humidity levels consistent with mold prevention should be maintained.

3. Loose architectural elements such as brackets or other elements subject to wind and adverse weather damage should be documented, removed and stored on site. Securely attached material should not be removed.

4. Any penetration, such as a louver, that is accessible to pests and/or animals, and is not equipped with a damper, should be covered. The covers should be removed if the equipment is operated at anytime during the mothball period.

5. Exterior structural steel framing should be free of rust or deterioration. Painting of exposed members is encouraged. All metal surfaces subject to rust or corrosion should be coated to inhibit such deterioration.

6. Some locations may be subject to flooding, high winds, and rain. Structures should be inspected prior to major storms to ensure structural elements such as windows and doors are secured. Flood mitigation procedures such as sandbags and floodgates may be required depending on the severity of the storm. Building inspections should take place following a storm (when conditions allow) identifying any 
damage which may need to be addressed. The applicable disaster preparedness plan should be consulted prior to and after major storms for guidance.

7. The exterior of a facility should be secured from unsupervised or unauthorized entry. Exterior access ladders should be removed and roof hatches secured from the interior if roof access is not required during the mothball period. Gates on any security fencing should be locked.

8. The appropriate facility official should be notified to define specific signage requirements.

9. A facility point-of-contact responsible for monitoring facility condition and coordinating any work requirements during the mothball period should be assigned.

b. Wood

Wood siding or trim that is deteriorated, warped, cracked or rotted, should be repaired or replaced as necessary to keep out moisture; repainting is generally warranted.

c. Masonry

All masonry walls including brick and concrete masonry units should be free of cracks, spalling, or holes. Reinforcing bars should not be exposed. If major repairs are required to preserve the structural integrity of the structure, then a structural engineer should be consulted to provide direction. Minor repairs should be addressed to preserve the building envelope.

d. Doors and Windows

1. All doors and windows must be secured. Exterior door locks should be changed in accordance with the applicable security procedures for building closures. Exterior windows should be secured in a closed position from the interior of the facility. All broken windowpanes or glazing should be removed and replaced. For security reasons, boarding up of windows may not be permitted.

2. Interior doors should remain open for cross ventilation purposes. Where appropriate, reinforce exterior doors and add additional locks.

3. If applicable, close exterior window or door shutters. Ensure caulking around doors and windows is undamaged; replace sealant if necessary.

e. Architectural Metals

All metal surfaces including iron, steel, tin and aluminum, or other metals subject to rust or corrosion should be coated to inhibit deterioration. Loose connections should be corrected.

f. Roof

1. It is essential roofs remain weather tight at all times. Roofs should be maintained in a safe condition and have no defects which might admit rain or cause dampness in the walls or interior portion of the building. Roofs are the most vulnerable elements on the building exterior. Use of "quick fix" solutions should be avoided as they will generally fail and may accelerate damage by trapping moisture.

2. If a roof needs moderate repairs to make it last an additional ten years then these repairs should be undertaken as a first priority.

3. Roof penetration flashing and seals should be inspected for integrity.

4. Gutters, roof drains, and downspouts should be inspected to verify that they discharge away from the building and that all joints are intact. Corrective measures should be taken as necessary. 


\section{Interior}

a. General

1. All structures must be rid of debris. Remove all bird dropping or other animal waste. Precaution should be taken during removal of toxic droppings from bats or pigeons. Remove all office equipment, furniture and kitchen appliances.

2. A final audit of the building should be done at the start of the mothball process. Take current moisture content reading for interior spaces and record the baseline reading for future monitoring. Moisture build up within a structure is almost inevitable when it is not in use. The problem starts when the structure is vacant and moisture build-up is uncontrolled. Once the exterior has been made weather tight and secure, it is essential to provide adequate air exchange within the building. Excessive build-up of moisture may also weaken the structural components. Poorly mothballed masonry buildings, particularly in damp and humid zones have been damaged on the interior with just one year of unventilated closure such that none of the interior finishes were salvageable when the buildings were reactivated.

3. All cipher locks on interior doors should be removed and returned to the appropriate office.

b. Finishes

Any paint that is in poor condition should be removed and subsequently re-painted. Follow proper precautions of material removal in regards to lead based paint and asbestos. Paint that is flaking, peeling or blistered is a possible indication of excessive interior moisture. Remediate any molded surfaces following all health precautions including any standing water. Remove and replace all suspended acoustical ceiling panels which have evidence of water damage. Remove any carpeting or floor or wall covering with water or mold stains. Broom clean all floors after floor finish removal. If there is mold or excessive interior moisture, the cause should be determined and rectified before the repainting of surfaces or the replacement of ceiling tiles

c. Cranes

All Bridge Cranes, Jib Cranes and Chain Hoists should remain in place. Deploy all hooks to floor level and coat wires and or chains with grease. Bridge Cranes should be parked adjacent to points of support such as runway columns, or beam brackets.

\section{Plumbing Systems and Equipment}

\section{General}

Moisture, corrosion, and freezing are the biggest detriments to the plumbing and water systems. Facility location will dictate precautions taken against potential flooding and geologic activity. Lack of air quality and temperature control will lead to excessive mold growth and freezing.

All pipe insulation located outside the facility should be checked and sealed weather tight. Any damaged pipe insulation located inside the facility should be repaired to prevent further deterioration. Pipe insulation known to have asbestos containing materials (ACM) should be documented and any damaged areas should be properly abated and repaired.

Pipe hangers should be thoroughly inspected for wear and replaced as necessary.

If the plumbing and domestic water system will not be operational during the mothball period:

1. All domestic cold and hot water lines should be isolated, drained, dried and sealed.

2. Traps, including water closets and urinals, should be kept full of water or mineral oil, or the use of a trap primer alternative should be installed to prevent sewer gasses from infiltrating the structure.

3. Drains (including floor drains) should be plugged.

4. Water heaters should be isolated, drained, and valves left open.

5. Drinking fountains and bubblers should be isolated, drained and valves left open. Refrigerant should remain in cooling units. 
6. Domestic water service to the building should be isolated, shut off and all stops and faucets should be opened to avoid pipe rupture from potential freezing conditions.

7. Ensure valves are prepared so that they will function upon re-activation without being cycled for the duration of the mothball period.

8. Plumbing fixtures should be wrapped and sealed in polyethylene to protect from dust and debris. Remove the batteries from "Touch Less" plumbing fixtures.

9. Utility hoses should be disconnected from exterior hose bibs and the hose bib valve should be left open. Hose bibs should be covered with mesh to prevent insect entry.

10. Sump pumps and sump alarms to a central monitoring station should remain active. Labels should be used to indicate these systems are to be left active.

If the plumbing and water system will be operational during the mothball period:

1. Traps should be kept full of water or mineral oil, or the use of a trap primer alternative should be installed to prevent sewer gasses from infiltrating the structure.

2. If the building will not be conditioned, alternative methods to prevent freezing should be provided.

3. Water used in plumbing fixtures should be treated to prevent mold growth.

4. Water heaters should be considered non-essential and should be placed in a mothball state as described above.

5. Drinking fountains and bubblers should be considered non-essential and should be placed in a mothball state as described above.

\section{Applicable Plumbing Systems}

All of the following systems listed are not applicable to every structure. The facility condition assessment (Section 2.4) should make note of which systems are applicable.

a. Restroom Facilities

1. Lavatories

2. Water Closets

3. Urinals

b. Water Heaters

1. Natural Gas

2. Electric

3. Instantaneous

c. Water Coolers

1. Drinking Fountains (Cold Water, Direct Expansion )

2. Bubblers (Ambient Water)

\section{d. Floor Drains}

1. Sanitary Sewer Drains

2. Storm Drains

a. Storm run-off sump pumps should remain operational and sump pump pits should be cleaned of debris.

3. Hazardous Chemical or Collection Drains

a. All collection tanks should be drained and inspected during condition assessment. Valves should be left open.

b. All collection pits should be clean, dry and void of debris.

4. Sewage Pumps

\section{E. Mechanical Systems and Equipment}

Moisture, corrosion, and freezing temperatures are the biggest detriments to mechanical and piping systems and to the structure itself. Uncontrolled moisture build up within a structure may weaken the structural components and 
induce severe mold growth to the point that the building is un-inhabitable and cost to re-activate is prohibited. Uncontrolled temperatures below freezing will result in ruptured piping.

\section{HVAC Systems and Equipment}

a. The status of the HVAC system during the mothball period affects the integrity of other systems within the building, and the building itself. Operational HVAC systems deter mold and mildew growth during the summer months by controlling indoor relative humidity. Operational HVAC systems also maintain the building above freeze levels during the winter months.

b. The age of the HVAC system should be considered in determining if mothballing is warranted.

c. If the HVAC system and all supporting systems (hot water, steam, natural gas, electrical power, chilled water, etc.) are to remain operational, they should be at a reduced capacity of $40^{\circ} \mathrm{F}$ dry bulb indoor temperature during winter and $80^{\circ} \mathrm{F}$ dry bulb indoor temperature during summer. Indoor relative humidity should be maintained at $70 \%$ or less throughout the building, to prevent mold growth. For an operational HVAC system during the mothball period:

1. The make-up water system should remain active.

2. Refrigerant monitors should remain active.

d. If the HVAC system will not be operational during the mothballed period:

1. Remove filters.

i. The refrigerant circuit should be inspected for integrity. Refrigerant should remain in the system during the mothball period. Periodic operation of the system should not be required. Refrigerant monitors and alarms should remain active.

ii. All ducting should be clean, dry, and protected from being exposed to factors which induce mold formation.

e. All duct and pipe insulation should be inspected for integrity and repaired as necessary. All duct and pipe insulation known to have ACM should be documented and any damaged areas should be properly abated and replaced with non-asbestos insulation.

f. All coils should be cleaned prior to deactivation.

g. As the structure will not be occupied during the mothball period, fresh air inlets should be sealed.

h. Exhaust fan entrances into the building should be sealed.

i. Penetrations in the building (air intakes and exhaust) should be evaluated for pest protection prior to deactivation. Any penetration, such as a louver, that is accessible to pests and/or animals, and is not equipped with a damper, should be covered. The covers should be removed if the equipment is operated at anytime during the mothball period.

j. List of Potential HVAC Equipment

All of the following systems listed are not applicable to each structure. The FCA should make note of which systems are applicable.

1. Heat Pumps

2. Ductless Split Systems

3. Roof Top Units

4. AC Window Units

5. Packaged Units

6. Computer A/C Units

7. Terminal Air Devices

8. Variable Air Volume Units

9. Fan Coils 
10. Geothermal Systems

11. Unit Heaters

12. Duct Heaters

13. Baseboard Heaters (Electric Wall Fin, Hot Water and Steam)

14. Radiant Heaters

15. Ventilators and Ventilation Fans

16. Exhaust Fans

17. Air Make-Up Fans

18. Air and Water Cooled Chillers

19. Absorption Chillers (drain all fluids including lithium bromide absorbent)

20. Cooling Towers. Cooling tower fill-baffling is usually PVC and deteriorated by UV light.

21. Humidifiers and De-Humidifiers

22. Water Make-Up Systems

23. Duct Systems

\section{Building HVAC Control Systems}

Moisture and corrosion are the biggest detriments to the control systems. Use of desiccant packages and sealing of control panels should be considered if the HVAC systems are to remain non-operational during the mothball period. Instruments used for control, such as temperature, flow, and pressure sensors should be protected from corrosive detriments. Service air used in pneumatic control systems should be shut off and depressurized. Direct digital control (DDC) programs should be backed-up electronically and properly stored.

All of the following systems listed are not applicable to every structure. The FCA should make note of which systems are applicable.
i. DDC
ii. Pneumatic
iii. Manual (Local)

\section{Rotating Equipment}

\section{a. General}

1. Rotating equipment (air handling units, pumps, compressors, etc.) not only has to be protected from corrosion, but also has to be protected from damage caused by non-use. Many pieces of rotating equipment can be protected from corrosion, but damage caused by non-use needs to be addressed and established during the PM phase of a project (rotation of shafts). Consumable parts, such as seals, will decay during the mothball period. In almost all cases, the manufacturer should be contacted for their recommended method of preparing their equipment for long term non-use.

2. Depending on the duration of the mothball period, performing PM on equipment may not prove to be the correct economic decision for the equipment. Smaller horsepower "off the shelf" equipment may be considered disposable versus performing yearly PM work over the duration of mothball. This should be established early in the project. Other items that are specialized and have long lead times typically will likely prove to be worth the cost to preserve properly. It is for this reason that the assumed duration of the mothball period needs to be identified prior to developing PM plans and procedures for equipment.

3. To minimize internal corrosion, close off all vents and openings, and completely fill casing with manufacturer's recommended lubricant or use a vapor phase corrosion inhibiter. Alternatively, consider adding volatile corrosion inhibitor in the correct proportion to the lubricating oil.

4. To prevent external corrosion, if unpainted, a recommended spray-on coating should be used (either as a light wax or liquid PVC).

5. Unless required for mothball, all rotating equipment should (where desirable) be separated from the piping system to allow independent mothball and PM items to be completed.

6. Rotating equipment will need to be de-energized based on the PM requirements established and the electrical requirements indicated in the Facility Mothball Plan. If the equipment does not require power during the mothball period, it should be deactivated once it has been prepared for mothball status. 


\section{b. Pumps}

1. Due to their simplicity of mechanical construction, centrifugal, reciprocating, and injection -type pumps lend themselves to effective and inexpensive preservation. Detailed disassembly of the pump is typically not required when preparing for long periods of idleness.

2. The method to preserve the pump should be evaluated for each pump. Depending on the type of lubrication system (oil filled or mist) it may be more economical to leave running in lieu of rotating on a PM program. In services where the process is considered corrosive, the protective measures are similar. The only differences are the manner and extent of cleaning.

3. Positive displacement pumps and pumps with mechanical seals need to be either properly placed in a mothball state or placed on a PM schedule to address the wear and possible seizing of the pump.

c. Compressors

The extent of protection given to centrifugal compressors depends on their type, size, and service. Some protective measures that may be taken include removing the cover from the case, cleaning the case and rotor thoroughly, coating them with oil, and cleaning the entire lube and seal oil systems. Another measure that may be taken is to fill the case with lube and seal oil systems with suitable oil. Alternative procedures may also be used to provide protection for compressors. Because of their high original cost, the protection afforded large reciprocating compressors should be extensive and detailed.

d. Boilers

Boilers should be placed in a mothball state to minimize corrosion. Fuel hazards and disposal should be evaluated. Depending on the type of boiler, there may be return-to-service requirements from local or federal environmental regulatory agencies.

e. Documentation

All PM information should be tracked and documented in the CMMS. Likewise, PM items which are no longer performed should be placed in an "inactive mode" for tracking in the CMMS. This allows the facility to determine exactly what is required for a restart of a facility when those assets are placed back in "active status" and outstanding PM items are noted.

\section{Piping and Vessels}

a. General

Piping systems consist of piping, valves, tanks, pressure vessels, and other equipment which carry or store a fluid and does not contain moving parts. The primary purpose of the piping system is to store or transfer fluids from one location to another. Regardless of the type of fluids these systems are exposed to, the method in which a mothball state is reached is similar with minimal exceptions.

Mothball of piping systems should be completed in a manner which has the priority of keeping the facility safe. To the extent practical, all piping should be clean, dry, and protected from being exposed to factors which induce corrosion. These include but are not limited to: general corrosion, galvanic corrosion, pitting corrosion, and microbiological corrosion. Corrosion prevention during the mothball period is essential to minimizing the damage that can result after a shutdown.

Piping systems which are considered to be in a "clean" service typically do not require special treatment preparing for the mothball period. These services include, but are not limited to, water, air, steam, and nitrogen. All fluids should be drained and removed from the piping. The piping should be dried using compressed air, nitrogen, or other approved method. Any moisture that is allowed to remain in the system will induce corrosion.

Piping systems which are considered to be in a "hazardous" service typically require additional steps to be performed prior to being considered in a mothball state. These services include chemicals which require special storage and disposal methods, and cannot be cleaned or drained directly to the sewer. All fluids should be drained and removed from the piping. These systems should be cleared of all remains using compressed air, nitrogen, steam, or other approved method. During the cleaning phase of hazardous 
systems the amount of waste created should be considered, as it will have an associated disposal cost. All fluid disposals must be in accordance with federal, state, and local environmental regulations.

Systems and components should be isolated from each other to create manageable zones for preserving. Systems that have large vessels or which are routed through numerous identifiable zones (buildings) may be separated using isolation blind fittings to make management of the system easier. The systems which cross multiple zones or buildings may need to be separated in identifiable and maintainable sections. Some of these may be required to have a different mothball requirement based on the facility shutdown status and schedule.

b. Preparation and Corrosion Control

1. How the piping is mothballed needs to be determined based on industry standards and the owner's preferences. It should be sealed and isolated, left open, protective coating applied, or purged/blanketed with dry air/nitrogen.

2. Several factors must be considered to determine which method and level of protection a piping system requires: the duration of the mothball status; current condition of the system; and location of the system.

c. Outdoor Piping

Piping which is to remain outside the building will be exposed to the weather and possibly additional outside interaction (personnel or equipment) if not properly protected. This piping should be protected both externally and internally. Any failed coating or insulation should be repaired (weatherproof) to protect the piping system from external corrosion. Insulation containing ACM should be addressed as part of the piping protection system and the overall facility environmental assessment. The piping may be protected internally from corrosion by either blanketing or purging the piping while in a mothball state. Isolating a system located outside from the portion of the system located inside of a building may be desired if blanketing or purging of that system is desired.

d. Indoor Piping

Piping which is to remain inside the building and protected from weather may not require as much protection as piping which is to remain outside. Piping that remains inside may not require any additional internal treatment or protection once all fluids have been removed from the piping and the internals have been verified to be clean. External protection should be limited to repairing any existing coatings (paint or insulation) which will continue to decay to an unacceptable condition during the shutdown.

e. Nitrogen Blanket

1. The use of an inert gas to control corrosion of the inside surfaces of equipment is a very effective method. Inert gases can only be used in systems that can be sealed and have a slight pressurization to them. Corrosion control is based on using an inert gas with oxygen content less than $1 \%$. Signage should be posted in the area.

2. In all cases ensure the piping is as clean and dry as possible. Insert line blind fittings to create manageable zones that can be slightly pressurized $(0.5+\mathrm{psig})$ using nitrogen or dry air if required. Provide a low flow and arrange for some simple telltale mechanism to show pressure, flow, and humidity.

3. When blanketing with an inert gas, the need for additional monitoring and signage should be evaluated. The decision should be based on location (inside or outside) and volume. The area should be verified safe before entry where an inert gas is present.

f. Liquid Filled

If vessels have liquid in them, employ some form of oxygen scavenger or anti-biological growth chemical (boilers). Piping which is to remain full of fluid should have a corrosion inhibitor injected or a method to provide a minimum flow to prevent stagnant conditions. 


\section{g. Neutralization}

Depending on the process and materials of construction, it may be desirable to apply a chemical coating system to neutralize the piping and vessels. There are many systems that could be applied and this should be evaluated based on the duration and cost for the mothball period.

\section{h. Mechanical Protection}

1. In addition to corrosion, piping and vessels located outside should be protected from severe weather and damage from events such as hurricanes, high winds, or vehicle traffic. Most equipment which is already located outside already has some means of protection from such sources of damage, but when all fluids are emptied some vessels will no longer have the expected associated weight and may require additional methods of protection.

2. Piping and vessels which contain internals (filters, traps, strainers, and exchangers) should be evaluated to determine if these internals should be removed, saved, or disposed of for later replacement.

3. Pipe hangers and supports which have moving parts may need to be protected (lubricated) from long term non-use with no movement.

4. Any radiation sources should be identified and removed from the system. These may include radar technology or level gauging.

5. Valves should be evaluated to determine what preparation is required prior to placing a system in a mothball state. Fresh lubrication may be required to protect valves which rely on normal usage to ensure proper operation. Evaluate to ensure valves are secured so that they will function without being cycled for the duration of the mothball period.

\section{F. Electrical}

Mothball considerations for the electrical power distribution system will be heavily dependent upon the established requirements imposed by the deactivation and essential mothball maintenance activities chosen for the mechanical, architectural, and structural aspects of the facility. The requirements for maintaining a secure facility, supporting the needs for fire detection, atmospheric and/or chemical monitoring, and provisions for safe facility entry and egress after deactivation also impose challenges that must be integrated into the mothball procedures.

\section{Lighting and Receptacles}

Lighting should be limited to the minimum necessary to satisfy interior and exterior security requirements, provide safe entry and egress for essential mothball maintenance activities, and to avoid affecting active facilities that may be interconnected with the lighting infrastructure of the mothballed facility.

Night light circuits should remain energized in mothballed facilities. Deactivation planning should begin by determining how the night light circuits are distributed throughout the panel boards in the facility. Pay attention to the methods of how the night lights are turned on and off. Night light circuits that are currently turned on and off by breakers intertwined in panel boards that will likely have equipment not desired to be accidentally activated should have alternative lighting panels and controls installed as part of the deactivation process.

Task or high bay lighting that is not shared by neighboring facilities and controlled remotely through an energy management control system (EMCS) should be deactivated at both the facility and at the EMCS central control site. Coordinate any required graphic user interface modifications with the applicable energy management function. Exit lighting and emergency egress lighting are not required to remain active in the facility because the facility will not be normally occupied by personnel. Emergency lighting with battery backups may be considered to be utilized in other active facilities. If the decision is made to leave these fixtures in the facility during the mothball period, the batteries should be removed from the units and from the facility.

Exterior lighting around entries should remain energized to assist with securing the facility. Lighting fixtures with integral photocells and/or lighting contactors with photocells should be installed during the deactivation process. 
Existing lighting with photocell capabilities should have those capabilities tested during the deactivation process to ensure proper operation. Parking lot lighting circuits fed from the facility distribution system should also remain energized. Again, the proper operation of the parking lot lights to activate only in low lighting situations should be verified during the deactivation process.

The requirement for maintaining power to receptacles should be made upon consideration of the planned activities during the mothball period. Receptacles supplying power to non-essential appliances, such as vending machines and office equipment, should be de-energized as high up in the electrical distribution system as possible. Receptacles that can be shown to be essential during the mothball period should be considered to be powered from circuits that are associated with panel boards that are already going to be energized during the mothball period, or from sources that can be easily turned on and off separately from the existing panel breaker (to help simplify the electrical isolation process).

Equipment with a cord(s) plugged into receptacle(s) should have those cord(s) removed from the receptacle(s), even if the equipment will remain in the facility during the mothball period. A trip hazard should not be created by the unplugging of equipment cords.

Inactive receptacles should be evaluated to determine if rodent and insect intrusion can be minimized by additional work to the receptacle during the deactivation process.

\section{Air Cooled Transformers and Substations}

Power will likely need to be maintained to various systems in the facility during the mothball period. Before the deactivation planning can proceed, there should be a task to identify all active power loads during the mothball period, to locate of all these loads and their power sources (record voltage, amperage, separate control power requirements, etc), to note any known mothball maintenance tasks with significant or specialized temporary power requirements, and to formulate a plan to consolidate as many of these sources as possible to help minimize the complexity of the electrical isolation plan.

Note whether the elevator and cranes will be operable during the mothball period. Also note whether the facility is fed from its own substation or is fed (in whole or in part) from a substation that is located at another facility, or that is shared by active facilities not to be deactivated.

For storage purposes of air cooled transformers and substations (here the term substation is inclusive of switchgear, air switches, motor control centers, and combination starters), note whether the facility HVAC system(s), air handler(s), or boiler(s) will be active during the mothball period. Space heater power will be required for moisture control in unheated climates. Care must be taken to prevent the accidental energizing of the substation through a back feed from the space heater power source. Consider the use of desiccant in the interiors of switchgear and motor control center compartments. Desiccant should not be placed in a location that causes a potential source of fire from the energized space heaters.

Inventory the electrical equipment and make sure each item is appropriately identified in the CMMS. Create a list so that all deactivated systems are placed in the appropriate status. Photographs should be taken of the equipment whenever possible in addition to recording the following information:

- Current physical condition of equipment

- Expected life of equipment

- List of major components that could be repurposed elsewhere on the Center/site

- Any useful comments about the systems

Collect any existing system documentation or identify where it is safely stored. Redline configuration controlled drawings (CCD) to show the current configuration of the facility including the necessary information to document how the facility has been isolated from the rest of the power distribution system. As part of the mothball process, any CCD documents that are modified should be updated. Once the facility has been officially placed in mothball status, all existing facility drawings and documents should be moved from the "current archive" section of the 
drawing management system to the "historical archive" section. Notify the power distribution computer model administrator (as applicable) to make sure the appropriate electrical equipment status is reflected in the model.

One of the most dangerous failure modes of electrical equipment that will not be energized for long periods of time results from the degradation of insulation due to moisture. If not identified and corrected, this degradation can result in a dangerous phase-to-phase or phase-to-ground fault upon re-energizing; therefore, identify all electrical equipment being deactivated and define the types of calibration and testing to be performed with insulation testing included as a high priority during the reactivation phase. Define a procedure to ensure relay and breaker calibrations should not be active during the mothball period. These suspended calibrations should be listed and marked as required during reactivation testing. Identify any other periodic maintenance items that need to be performed during the mothball period.

Identify any existing problems with each individual or appropriately grouped pieces of equipment for future evaluation or to be addressed before completing the reactivation process. Identify by project tracking number any existing designs or partially completed projects that impact the facility electrical system.

\section{Oil Filled Transformers}

Leave oil filled transformers energized if at all possible to promote oil circulation through the radiator fins. Loading should be at least 25 percent of nameplate kVA to avoid poor energy efficiency. A transformer with less than $25 \%$ loading should have its loads moved to other power sources and then either eliminated or repurposed at another facility.

Verify proper oil level during the deactivation process. Repair any leaks around the drain valve. Fill the space above the oil level with nitrogen. Leave with a positive pressure of approximately 2 psig to aid with the detection of leaks.

Protect the bushings against mechanical damage. Remove any existing animal nests.

\section{Motors and Generators}

Motors and generators will need protection from weather (outdoor locations), moisture condensation, dust, insects, and small animals. Motors $50 \mathrm{HP}$ and below should be considered for demolition or repurposing in another facility. These motors can usually be replaced for less than the cost of labor to properly prepare them for long term mothball storage. Disconnected wiring to all motors should be protected from damage caused by rodents. The wiring should also be protected from accidental energizing through the use of applicable lockout/tagout processes for energized systems.

Fasten covers over all vent openings to prevent entry by insects, rodents, birds and other animals.

If the motor has condensation drain plugs, remove these and wrap them in approximately 6 mil of plastic wrap. Attach this drain package to the motor at the drain openings so these are not lost or overlooked when the motor is placed back into service.

The ideal mothball scenario would be to wrap the entire motor in approximately 6 mil of plastic wrap and enclose small packs of desiccants. Utilize desiccant that has a visual indicator (i.e. changes colors) when the desiccant is full of moisture. Tape the loose ends to provide total protection from dirt, moisture, and other contaminants. This ideal scenario may not always be possible or feasible to execute. In those cases, more time and/or costs should be estimated as part of the reactivation effort for cleaning and inspection of unwrapped motors.

Energize the motor space heater if so equipped. If there is no electric space heater, the motor is probably not worthy of protecting during the mothball period and should be considered for demolition or repurposing in another facility. Consider relocating motors that are not located on raised bases to skids or pallets if there is possibility of water damage. If possible, have a minimum of 6 mils plastic wrap between the skid/pallet and the motor to prevent direct contact. 
Drain associated equipment such as liquid rheostats to avoid corrosion issues. Properly dispose of the (typically) salt water solution.

Portable generators (diesel, gasoline, or natural gas) should be removed and repurposed at another facility or placed in storage away from the facility. Consult the manufacturer of generators for special precautions to prevent damage. In general, permanent diesel and gasoline driven generators should have the fuel tank, lubricating oil sumps and/or tanks, as well as the oil filter and fuel pump housings drained. A corrosion inhibiting solution may be placed in the engine crankcase and/or fuel pump housing depending on the manufacturer's recommendations. The manufacturer may also recommend draining and flushing the cooling system and then refilling the cooling system with a 40/60 anti-freeze/water mixture that may also contain some type of corrosion inhibitor. Any exhaust pipes, breathers, and other vents should be sealed with the 6 mil plastic wrap if possible. The relative humidity inside the generator should not exceed $30 \%$ to minimize moisture accumulation in the insulation.

For DC and other AC motors with wound rotors containing commutator and slip rings, brushes should be raised in or removed from contacting the commutator or slip ring while the motor is in storage. Commutators and slip rings should also be sealed with 6 mil plastic wrap if possible.

For motors with grease-lubricated bearings planned to be stored beyond three years, remove the bearings. Support the rotor as required to accommodate the removal of the bearings. Do not remove oil-lubricated bearings from motors. The oil in the bearings helps to protect the shaft. The removal of these bearings would cause more corrosion on the shaft. Drain and fill the lube oil system with approved lubricant. Addition of a corrosion inhibitor of not more than $10 \%$ (by volume) is acceptable as long as the fluid is replaced with operating lubricant prior to re-starting the equipment.

\section{UPS and Battery Systems}

The uninterruptable power supply (UPS) system is typically a combination of circuit breakers, air cooled transformers, electronics, and batteries. If the facility will remain climate controlled, the UPS can be stored in place. It should be disconnected from the power supply as well as any associated batteries. If the facility will not be climate controlled, the UPS should be removed and stored in a climate controlled location or repurposed for another facility.

Maintenance free (gel cell) batteries typically require replacement after five years of service, so these batteries should be removed during deactivation. Wet cell batteries will need to be removed from the facility if the battery charger and the exhaust system where the batteries are located cannot remain energized. Hydrogen gas will accumulate in rooms where the batteries are charging; thereby causing an explosion hazard if the exhaust system is not active. If the batteries will not be in a conditioned air climate, they should be removed, even if the charger and exhaust system can remain energized.

\section{Fire Detection Systems}

In general, sprinkler systems should be deactivated except in facilities where a fire could spread to an active facility occupied by personnel. Direction should be obtained from the fire chief (or equal) on a case by case basis, during the development of the deactivation procedures. When the sprinkler systems are deactivated, flow and tamper switches should also be removed from the mothballed facility during the deactivation process. Fire detection systems should remain operational. Power to the fire control panels should be relocated to panel boards that will be energized during the mothball period, or from sources that can be easily turned on and off separately from the existing panel breaker (to help simplify the electrical isolation process). Repairs of identified failed and faulty system components should be made during the deactivation process. Coordinate with the fire chief (or equal) to avoid compromising the safety of the facility during the deactivation process.

Chemical and atmospheric monitoring systems that are connected to the fire control panels should be disconnected from the fire control panels once the monitored process system hazard (oxygen deficiency, combustible concentration of gas, presence of natural gas, etc) has been disconnected outside of the deactivated facility and confirmed to no longer be a safety and/or environmental hazard. Piping systems should be confirmed to be completely clean as prescribed by the piping systems sections of this document. A high priority should be made to deactivate as many of these monitoring systems as possible to avoid the preventive maintenance that is required to

21

American Institute of Aeronautics and Astronautics 
sustain these systems during the mothball period, and to avoid maintaining the facility temperature within the typical operating temperature limitations of the monitoring equipment $\left(0\right.$ to $\left.120^{\circ} \mathrm{F}\right)$.

\section{Environmental Monitoring Systems}

Environmental monitoring systems that are not connected to the fire detection system are also not typically integrated into the equipment control circuits to automatically shutdown that equipment upon approaching a process limit (e.g. oil release to the sump). The alarms that are routed to a facility control room or other normally occupied area are no longer effective lines of defense to a potential release or incident once the mothballed facility is no longer normally occupied. These alarms should be evaluated to determine if their relocation to a normal mothball period entry location or if the installation of an external beacon(s) during the deactivation process is necessary. The associated preventive maintenance required to sustain these monitoring systems during the mothball period and any operating temperature limitations imposed on the mothballed facility should be included as part of this evaluation. Power to any retained monitoring alarms should be relocated to panel boards that will be energized during the mothball period or else from sources that can be easily turned on and off separately from the existing panel breaker (to help simplify the electrical isolation process).

Sump pumps should remain operational during the mothball period. Repairs should be made during the deactivation process. There should be a risk based assessment completed to determine how often the sump pumps will be checked for proper operation during the mothball period. There may need to be special instructions documented in weather emergency plans depending on the typical flooding levels (and other weather related hazards) and the storage of critical equipment in the mothballed facility. If there will be materials in the mothballed facility not permitted to enter the storm drain system, then additional safeguards to prevent the release of this material into the storm drain system should be implemented during the deactivation process.

\section{Security Monitoring and Access Systems}

An inactive facility must be secured to prevent unauthorized access and injury to personnel. An assessment of the existing facility security system should be made early in the deactivation process, as this assessment may restrict how the facility power distribution system is deactivated.

Power to any installed intrusion alarms or security systems should remain active. Plans should be made to consolidate and/or relocate power circuits associated with the security equipment into panel boards that are already constrained to be energized during the mothball period, or from sources that can be easily turned on and off separately from the existing panel breaker (to help simplify the electrical isolation process). Coordinate with the site security management to avoid compromising the security of the facility during the deactivation process.

Power to installed security cameras should remain active. Plans should be made to consolidate and/or relocate power circuits associated with the security cameras into panel boards that are already constrained to be energized during the mothball period, or from sources that can be easily turned on and off separately from the existing panel breaker (to help simplify the electrical isolation process). The facility lighting requirements are not affected by the use or non-use of security cameras.

Power and communications required for identification controlled entry should remain active unless the security manager determines that changing the lock cores is the preferred method for securing the mothballed facility. Work may be required during the deactivation process to ensure these controlled access systems are maintainable during the mothball period. Any associated communications work required for proper security camera operations during the mothball period should also be completed during the deactivation process. Security and fire alarm communication between the mothballed facility and site central monitoring offices should be verified during the deactivation process. Coordinate with the site security manager to avoid compromising the security of the facility during this verification process.

Remove cipher locks from the facility and coordinate the removal with the site security manager during the deactivation process. The configuration and security requirements of the reactivated facility should determine whether these cipher locks need to be reinstalled during the reactivation process. 


\section{G. Communication Systems}

Because the mothballed facility will not be normally occupied by personnel, most communications and network equipment should be removed during the latter stages of the deactivation process. The coordination of equipment removal should be completed at the direction of the appropriate communication and network functions. The relative network position of the mothballed facility for utility metering, network gateways, etc., should be evaluated during the deactivation process. Depending upon the configuration of these network systems, there may need to be work performed during deactivation to ensure continued normal communication and network operations at other active facilities. Pull stations should remain active.

\section{H. Data Acquisition Systems (DAS) and Facility Automation Systems (FAS)}

The following section provides guidance for the development of procedures to deactivate facility DAS/FAS equipment.

Identify Subject Matter Experts (SME) for major DAS \& FAS systems. These people will be resources for the deactivation and their names should be recorded in the deactivation report.

Inventory FAS/DAS systems and ensure they are in the CMMS. Create a list to ensure all deactivated systems are placed in the appropriate status. The following information should be recorded for each system:

1. Current state of hardware \& software

2. Expected life of hardware \& software

3. List of major components that could be repurposed elsewhere on the Center (include inventory and serial numbers)

4. Any useful comments about the systems

5. List maintenance and diagnostic tools that will be needed or deemed useful for system reactivation

Notify the applicable computer security officer (OSCO) of facility DAS/FAS deactivation. Provide OSCO with a list of information technology (IT) assets (include identifying information such as inventory number, serial number, etc. and status) so that the applicable system security plan (SSP) can be updated. Relocated and repurposed IT assets should be identified with new location information.

Collect any existing system documentation or identify where it is safely stored as part of the project archives.

For FAS/DAS systems, baseline and document each software product, following applicable FAS/DAS configuration management $(\mathrm{CM})$ plans. Remove any backup batteries from logic processors or other equipment that will not be powered during the mothball period.

For any FAS/DAS dedicated personal computers, create a backup or image of each drive. Locate any FAS programming stations or computers; identify them as such. Record the pertinent licenses or development software on each. Locate, or create a procedure to shut down each system.

Investigate if there are any on-going/annual software maintenance fees or licenses. Work with the FAS/DAS system administrators to determine the most cost-effective way to address the items on this list.

Identify all DAS equipment being deactivated that requires calibration. Define a procedure to ensure these calibrations will no longer be active; this list will be required during the reactivation process. Identify any other periodic maintenance items that may need to be performed during the mothball period. Complete an assessment to determine if instrumentation (research/data collection and process related) should remain in place or relocated during the deactivation process.

Identify any existing problems with each system, for future evaluation or reactivation. Identify (by tracking number) any existing designs or partially completed projects that impact facility FAS/DAS systems. Include this information in the project archive with the other system documentation collected during the deactivation process. 
A conditioned space will greatly improve the chances of the DAS equipment returning to normal operation after a shutdown, as these systems are greatly impacted by moisture. Determine during deactivation if the facility control room HVAC system will be active during the mothball period. If not, determine if DAS hardware relocation is feasible, or if the equipment should be considered for repurposing at other active facilities.

Verify the accuracy of all inventoried equipment in the CMMS or other applicable database (user, custodian, and location), making all necessary corrections and relocation/repurposing adjustments. No inventoried equipment should be relocated or repurposed without completion of these actions.

\section{Food Service Equipment and Storage}

Contact the applicable real property manager for logistical requirements for the equipment indicated in this section.

\section{Refrigerators}

Remove all food and ice. The refrigerator should be cleaned and disinfected, and power should be disconnected to the refrigerator.

\section{Ice Machines}

Ice machines should be considered non-essential. The unit should be drained with drainage valves left open. The unit should be wrapped and sealed in polyethylene to protect from dust and debris.

\section{Cooking Equipment}

All cooking equipment should be cleaned and disinfected, and power should be disconnected from all cooking equipment (stoves, microwaves, etc.).

4. Food Storage Lockers and Vending Machines

All food should be completely removed from the facility and the unit(s) should be wiped clean and disinfected to deter rodents and pests. Non-government owned vending machines should be removed by the owner/supplier.

\section{J. Office Furnishings}

Removal, storage, and preservation of office furnishing should be at the discretion of real property manager.

\section{Preservation and Maintenance During Mothball Status}

This Section outlines guidelines and recommendations for developing the documentation for the PM plan that will be used to maintain the facility, systems, and equipment during mothball status. All personnel indicated in Section $\underline{2.2}$ should review and approve the plan prior to implementation.

\section{A. Fire and Life Safety}

An industrial hygienist should evaluate the building if facility maintenance personnel need access during the mothball period. If there is an air quality issue, personal protective equipment will be needed, or the problem will need to be corrected.

The main valve on the fire riser (main isolation valve) system should be activated yearly. The fire chief (or equal) should determine if other fire system valves are to be operated during the mothball period.

Refer also to Section 4.6.6 for further information concerning the fire detection system. 


\section{B. Environmental}

\section{Landscape Maintenance}

Vegetation around the building should be pruned back from the walls a minimum of twelve inches to allow good airflow. Overhanging dead tree limbs and branches should be removed. Ensure foliage is not in direct contact with the structure. The property grounds should be maintained at all times, the grass should not exceed six inches in height to aid in visual inspections of the roof drip-line and building foundations. Remove weeds from around utility areas and sidewalks.

\section{Animal and Pest Control}

Remove any existing colonies or nests of insects, rodents, snakes or other harmful pests. All surrounding grounds should be maintained free from any accumulation of garbage or a blighting influence such as stored materials which may harbor insects, rodents, snakes or other harmful pests. Monitor and inspect all seals of accesses such as vents, grills, louvers and replace wire screens as necessary to prevent intrusion to the building interior. All premises should be maintained so as to prevent the accumulation of stagnant water when such water causes a hazardous or unhealthy condition, become a breeding area for insects or which is causing soil erosion or damage to foundation walls. Treat damp or infected wood with insecticides or preservatives.

\section{Building Structure}

\section{Exterior}

a. General

1. Regularly scheduled inspections and maintenance are vital for successful mothballing. Maintenance and inspections are preventive measures against damage from the elements or neglect. After structures have been identified for temporary closure, gone through stabilizing and a condition assessment, an inspection form and schedule should be developed to address the individual conditions and concerns of each structure. Each structure should be visited at least once a month. Minor repairs should be addressed during the mothball period; if major repairs are necessary, consultation with a structural engineer is required. If replacement of damaged or deteriorated materials is required, then it should be done as soon as possible and should only address the damaged sections. All buildings or structures and all parts thereof should be maintained in a safe and sanitary condition.

2. Inspect all exterior wall surfaces for breaks, holes, loose or missing materials to prevent deterioration. All exterior surfaces should be repaired and protected as necessary including but not limited to decks, platforms and fences. Every foundation, exterior wall, roof and all other exterior surfaces should be maintained in structurally sound and weather tight condition. Cracks in concrete or masonry walls will require determination as to whether the crack is active (continuing to expand) or relatively dormant by use of a crack monitor. A widening or shearing of the crack may indicate structural issues; dormant hairline cracks can generally be left alone. Repairs can re-establish structural integrity with a dormant crack; however, if a crack is active then consultation with a structural engineer is required to determine the cause and recommended repairs.

3. Any structural member with evidence of deflection (bending or sagging) will need to be investigated by a Structural Engineer and repaired as directed.

4. Potential points for water intrusion, like crawlspace openings and basement louvers or windows should be blocked and the water diverted away from the building; however, basement and crawlspace relative humidity levels consistent with mold prevention should be maintained.

5. Securely attached material should be inspected for correct and proper attachment. All loose rivets/bolts or other connections should be replaced or tightened. 
6. Inspect all exterior structural steel framing for indications of rust or deterioration. All metal surfaces subject to rust or corrosion should be cleaned and coated as necessary to inhibit such deterioration.

7. Flood mitigation procedures such as sandbags and floodgates may be required at a facility depending on the severity of a storm. Building inspections should take place following a storm to identify any damage which may warrant addressing. The applicable disaster preparedness plan should be consulted prior to and after major storms for guidance.

8. Roof hatches and fence gates should be inspected to ensure they are secured to deter any unauthorized or unsupervised entry to the facility.

b. Wood

Repairs or replacement should be made to wood siding or trim that is deteriorated, warped, cracked or rotted; repainting is generally warranted. Provide proper drainage so that water is not allowed to stand on any flat horizontal surface. Retain coatings such as paint that help protect the wood from moisture and ultraviolet light. Paint removal should be considered only where there is paint surface deterioration. Inspect painted wood surfaces to determine whether repainting is necessary or if cleaning is adequate.

c. Masonry

All masonry walls including brick and concrete masonry units should be free of cracks, spalling, or holes. Reinforcing bars should not be exposed. If major repairs are required to preserve the structural integrity of the structure, then a structural engineer should be consulted to provide direction. Minor repairs should be addressed to preserve the building envelope. Deteriorated mortar from the joints of a masonry wall should be examined or analyzed to determine whether the extent of deterioration is affecting the wall's integrity. Re-pointing of mortar joints may be required to provide a weather tight enclosure. Stains on masonry wall should be examined or analyzed to determine its cause. Discoloration may indicate a source of water to be addressed or efflorescence (a white, powdery stain resulting from leaching of lime) which may indicate a more inherent problem with the integrity of the wall.

d. Doors and Windows

All doors and windows should be inspected to ensure they are secure from the exterior. All broken windowpanes or glazing should be removed and replaced.

Interior doors should remain open for cross ventilation purposes. Replace sealant if necessary.

e. Architectural Metals

Inspect all metal surfaces including iron, steel, tin and aluminum or other metals for indications of rust or corrosion. All metal surfaces should be coated as necessary to inhibit such deterioration. Loose connections should be corrected.

i. $\quad$ Roof

Roofs should be maintained in a safe condition and have no defects which might admit rain or cause dampness in the walls or interior portion of the building. Roofs should be inspected for moisture build up, insect damage, proper anchorage and deteriorated roof fasteners. Assuming the roof surface was adequate at time of mothballing the use of shingle replacement, panel replacement, roll roofing patching or spray roofing where necessary is acceptable.

Gutters, roof drains and downspouts should be cleaned and inspected to verify that they discharge away from the building and that all joints are intact. Corrective measures should be taken as necessary.

\section{Interior}

a. General

1. Once the exterior has been made weather tight and secure, it is essential to provide adequate air exchange within the building. Without adequate air exchange humidity may rise to unsafe levels, and mold, rot and insect infestation are likely to thrive. Utilization of HVAC systems in summer is recommended and will 
require electrical service. For masonry buildings it is recommended to keep the interior temperature above the spring dew point to avoid damaging condensation. The need for summer internal conditioning may outweigh the winter requirements. Minimal internal conditioning may still yet foster mold and mildew if the weather pattern is damp. Monitoring the property during the mothball duration will provide information on the effectiveness of measures taken and re-evaluation can then take place. Covers installed over air intakes and exhausts should be removed if the equipment is operated at anytime during the mothball period.

2. Remove all bird dropping or other animal waste. Precaution should be taken from toxic droppings from bats or pigeons. Remove all office equipment, furniture and kitchen appliances.

b. Finishes

Any paint that is in poor condition must be removed. Follow proper precautions of material removal in regards to lead based paint and asbestos. Remediate any molded surfaces following all health precautions including any standing water. Remove and replace all suspended acoustical ceiling panels which have evidence of water damage. Remove any carpeting or floor or wall covering with water or mold stains. If there is mold or excessive interior moisture, the cause should be determined and rectified before the repainting of surfaces or the replacement of ceiling tiles.

c. Cranes

All bridge cranes, jib cranes and chain hoists should be operated on a periodic basis to eliminate the possibility of bearing distortion, flat spotted tires or dry rotted seals. Bridge cranes should be parked adjacent to points of support such as runway columns, or beam bracket.

\section{Plumbing Systems and Equipment}

1. If the plumbing and domestic water system will not be operational during the mothball period, perform regular inspections to ensure the protection methods are maintained.

2. If the plumbing and domestic water system will be operational during the mothball period, perform regular inspections and operation to ensure integrity of the systems and associated fixtures. Standard operational PM items should remain in place.

\section{E. Mechanical Systems and Equipment}

\section{HVAC Systems and Equipment}

a. If the HVAC system and all supporting systems (hot water, steam, natural gas, electrical power, chilled water, etc.) are to remain operational, it should be at a reduced capacity $\left(40^{\circ} \mathrm{F}\right.$ dry bulb winter, $80^{\circ} \mathrm{F}$ dry bulb summer, $70 \%$ relative humidity). During the mothballed period, perform regular monthly inspections to ensure integrity of the systems and that relative humidity $(\mathrm{RH})$ of the interior space is $70 \%$ or below. If $\mathrm{RH}$ is above 70\%, the set point temperature of the HVAC system should be increased to keep the interior space at $70 \%$ RH or below. Standard operational PM items should remain in place.

b. If the HVAC system will not be operational during the mothballed period, perform regular inspections to ensure the protection methods are maintained.

c. Covers installed over air intakes and exhausts should be removed if the equipment is operated at anytime during the mothball period.

\section{Building Automation Control Systems}

a. If the HVAC system is to remain operational during the mothballed period, the system should be monitored for operation and temperature adherence. 
b. If the HVAC system will not be operational during the mothballed period, each control panel and thermostat should be inspected for physical damage and to ensure seals are intact.

\section{Rotating Equipment}

a. Rotating equipment should be maintained to minimize corrosion activities as well as mechanical damage. Maintenance should include necessary equipment rotation or operation and fluid changes.

b. The maintenance required during the mothball period should be minimized as it could create additional utilities and other items to be required. Large pumps and motors will require additional electricity to rotate.

\section{Piping and Vessels}

When placed in mothball status properly, piping systems with no moving parts need to be inspected to ensure the protection methods are maintained and noted during the routine inspections. Any additional inspections which may become due during the mothball duration should be evaluated as to whether continuing to perform them is required.

\section{F. Electrical}

Electrical mothball maintenance will be primarily driven by the essential mothball maintenance activities chosen for the mechanical, architectural, and structural aspects of the facility.

\section{Lighting and Receptacles}

Active interior lighting that has failed during the mothball period should be repaired or replaced. Night lights should be repaired or replaced when there is an immediate safety or security hazard caused by the loss of lighting or when over half of the night lights are not functioning. Exit lighting and emergency egress lighting are not required to remain active in the facility because the facility will not be normally occupied by personnel.

Active exterior lighting should be repaired or replaced when there is an immediate safety or security hazard caused by the loss of lighting.

There are no requirements for receptacle maintenance during the mothball period.

\section{Air Cooled Transformers and Substations}

There are typically no requirements for maintenance of these systems during the mothball period. If utilized, space heater operation should be checked for proper operation. Replace the desiccant when the indicator color changes to show moisture laden.

\section{Oil Filled Transformers}

An oil-filled transformer subject to polychlorinated biphenyl (PCB) testing should be inspected at the five-year inspection date even if the transformer is considered to be mothballed. The PCB testing should continue to be completed by the electrical maintenance group and will not fall under the jurisdiction of the environmental branch. If the determination is made to remove a transformer from service, that date should become the "out of service" date for the transformer. The environmental manager should be notified in order to update the oil-filled equipment inventory. The out of service transformer must be removed from center within one year of being marked out of service.

\section{Motors and Generators}

Periodically check the protective wrap on the motor. If there is damage to the wrap but no obvious signs of rodent or insect intrusion, then apply patch overlays to the protective wrapping and generously apply tape to discourage future intrusions. Replace desiccant when the indicator color changes to show moisture laden. If space heaters are used, check for proper operation. 


\section{UPS and Battery Systems}

Where the conditions allow batteries to remain on and charging (refer to the discussion under the deactivation section of this report), the batteries should be equalized once a month in conjunction with a routine battery inspection.

\section{Fire Detection Systems}

Fire detection systems should remain operational (see other mothball maintenance requirements in Section 4.1). Preventive maintenance programs associated with the fire detection system should be stopped one week before the facility status is scheduled to change to inactive.

Repairs and replacements should be made to failed and faulty system components during the mothball period. Repairs and replacements should be conducted for the purpose of maintaining the basic early warning functionality of the system and not on the repair or direct replacement of every individual component. For example, if there are four smoke detectors in a room and one of those detectors failed, that failed detector would not necessarily be replaced unless two or more of the other smoke detectors had previously failed and not been replaced.

\section{Environmental Monitoring Systems}

Environmental monitoring systems that are not connected to the fire detection system should be evaluated to determine if relocation or if the installation of an external beacon(s) during the deactivation process is necessary to ensure any active alarms can be acknowledged once the facility is not occupied.

Sump pumps should remain operational during the mothball period. There should be a risk-based assessment completed to determine how often the sump pumps will be checked for proper operation during the mothball period. There may need to be special instructions documented in the weather emergency plans depending on the typical flooding levels and the storage of critical equipment in the mothballed facility.

\section{Security Monitoring and Access Systems}

An inactive facility must be secured to prevent unauthorized access and injury to personnel. Power and communications required for any installed intrusion alarms, security systems, security cameras, and identification controlled entry systems should remain active unless the applicable security manager determines otherwise during the deactivation process. The facility lighting requirements are not affected by the use or non-use of security cameras.

\section{G. Communications}

The mothballed facility will not be normally occupied by personnel, so most communications and network equipment should be removed during the latter stages of the deactivation process.

Any personnel planning to enter the facility during the mothball period need to be made aware during the preparations of safe plans of actions or other job hazard analysis that alternate communications plans (e.g., emergency/911) need to be in place and tested. Personnel should not call 911 to determine if the alternate plan works. Rather, personnel should check to make sure there is adequate radio reception or cell phone coverage in the planned working area prior to executing the work instruction.

\section{H. Data Acquisition Systems (DAS) and Facility Automation Systems (FAS)}

The following provides guidance for the development of procedures to perform essential maintenance on facility DAS/FAS equipment during the mothball period. 
For all FAS/DAS systems identified during the deactivation phase, research the recommended maintenance for each system. (Note: If the systems are powered down, no maintenance should be required other than periodic inspection to ensure no environmental issues have damaged the systems.)

Examine any maintenance items uncovered during the deactivation phase. Make sure these maintenance items can be supported by the method of facility deactivation (required utilities are active, etc.).

Annually inventory the systems to insure that critical system components have not been scavenged.

\section{Reactivation of a Facility}

This section outlines guidelines and recommendations for developing the documentation for the reactivation procedures that will be used to reactivate a facility from mothball status to "active" status. All personnel indicated in Section 2.2 should review and approve the procedure prior to proceeding with the reactivation.

1. As part of the reactivation procedure, the document should provide an executive summary (narrative) explaining why the facility was deactivated, the new purpose/function of the facility, and any outstanding issues and/or safety concerns, such as indicating any damaged equipment. In addition, the executive summary should clearly identify equipment that requires repair, reconditioning, overhaul, and maintenance to reactivate from a mothball status.

2. An assessment should be considered to define upgrades to the system(s) needed to meet current codes. Equipment and items that may have been permitted at the time the building was initially mothballed may no longer be allowed by code. Prior to operation, the facility must meet applicable standards, and also be approved by appropriate SMEs as being ready for operation. Areas of particular concern are:

A. Life safety codes (number and type of exits, sprinklers, occupancy requirements).

B. Sanitation requirements (number and type of fixtures, materials for floors and walls).

C. Electrical requirements (may have to bring up to current standard). Local codes may be more restrictive than national codes and may contain provisions that could involve major reconstruction. A thorough evaluation must be made to ensure code compliance and to estimate the costs of reactivation of the facility versus new construction.

3. Upon reactivation of a facility, all configuration controlled drawings need to be field verified.

4. In the event the facility is only partially reactivated, a review should be completed to determine which systems or partial systems are required.

\section{A. Fire and Life Safety}

Two audits of the facility should be conducted: safety/health and fire/life. Direction should be obtained from the fire chief (or equal) during the development of the reactivation procedure. If the sprinkler system was deactivated, then the system and all related components need to be inspected prior to reactivation. In addition, only personnel from the fire department should reinstall fire extinguishers and SCBA devices in the facility.

\section{B. Environmental}

\section{Landscape Maintenance}

Vegetation around the building should be pruned back from the walls a minimum of twelve inches to allow good airflow. Overhanging dead tree limbs and branches should be removed. Ensure foliage is not in direct contact with the structure. Remove weeds from around utility areas and sidewalks.

\section{Animal and Pest Control}


Remove any existing colonies or nests of insects, rodents, snakes or other harmful pests. Monitor and inspect all seals of accesses such as vents, grills, louvers and replace wire screens as necessary to prevent intrusion to the building interior. Treat damp or infected wood with insecticides or preservatives.

\section{Building Structure}

\section{Exterior}

a. General

1. Inspect all exterior wall surfaces for breaks, holes, loose or missing materials. All exterior surfaces should be repaired and protected as necessary including but not limited to decks, platforms and fences.

2. Inspect all exterior structural steel framing for indications of rust or deterioration. All metal surfaces subject to rust or corrosion should be coated as necessary to inhibit such deterioration.

3. Exterior ladders should be re-installed to allow access where required.

b. Wood

Wood siding or trim that is deteriorated, warped, cracked or rotted should be repaired; repaint as required.

c. Masonry

All masonry walls including brick and concrete masonry units should be free of cracks, spalling, or holes. Reinforcing bars should not be exposed. If major repairs are required to preserve the structural integrity of the structure, then a structural engineer should be consulted to provide direction. Minor repairs should be addressed to preserve the building envelope.

d. Doors and Window

File request with the appropriate function that the master cores on exterior locks be replaced. All doors and windows should be inspected to ensure they are secure from the exterior. All broken windowpanes or glazing should be removed and replaced. Replace sealant and caulking if necessary.

e. Architectural Metals

Inspect all metal surfaces including iron, steel, tin and aluminum or other metals for indications of rust or corrosion. All metal surfaces should be coated as necessary. Loose connections should be corrected.

f. Roof

Roofs should be in a safe condition and have no defects which might admit rain or cause dampness in the walls or interior portion of the building. All roof surfaces should be heavily scrutinized as weathering will most certainly have occurred, and the duration of the mothball of the facility will have an impact on the life expectancy of the roof covering.

Gutters, roof drains and downspouts should be cleaned and inspected to verify that they discharge away from the building and that all joints are intact. Corrective measures should be taken as necessary.

\section{Interior}

a. General

Prior to activation of any mothballed facility, the environmental management function will be required to assess any building interior for the health and safety of future inhabitants. Air quality will be of primary concern. All structures must be rid of debris. Remove all bird droppings or other animal waste. Precaution should be taken from toxic droppings from bats, pigeons, or other animals.

b. Finishes

Any paint that is in poor condition must be removed. Follow proper precautions of material removal in regards to lead based paint and asbestos. Remediate any molded surfaces following all health precautions including any standing water. Remove and replace all suspended acoustical ceiling panels which have 
evidence of water damage. Remove any carpeting or floor or wall covering with water or mold stains. If there is mold or excessive interior moisture, the cause should be determined and rectified before the repainting of surfaces or the replacement of ceiling tiles.

c. Cranes

All bridge cranes, jib cranes, and chain hoists should be thoroughly inspected for bearing distortion, flat spotted tires or dry rotted seals. All lifting devices will need to be recertified.

\section{Plumbing Systems and Equipment}

Reactivation should be reverse of the methods used to initially mothball the facility. Each fixture and the domestic water piping system must be evaluated based on the preservation which was/was not performed to determine what needs to be completed prior to reactivating. Acceptance tests should be performed as if the system(s) were going through a new start up procedure.

\section{E. Mechanical Systems and Equipment}

\section{HVAC Systems and Equipment}

Reactivation should be the reverse of the methods used to initially mothball the facility. Each system must be evaluated based on the preservation which was/was not performed to determine what needs to be completed prior to reactivating. Acceptance tests should be performed as if the system were going through a new start up procedure.

\section{Rotating Equipment}

a. Preparation

1. Pumps will need to be disassembled, rebuilt, reinstalled and made operational for testing prior to placing back into service.

2. Reactivate all assets in the CMMS and determine extent of past due PM items and/or equipment needs.

3. When replacing equipment, new technology should be considered in lieu of in-kind.

\section{Piping and Vessels}

a. Preparation

Reactivation should be based on the methods used to initially mothball the facility. Each system must be evaluated based on the preservation which was/was not performed to determine what needs to be completed prior to reactivating. All safety and environmental considerations need to be reviewed as part of the reactivation.

All piping systems should have inspection criteria examined and updated. Overdue inspections need to be performed and recertification of the systems completed.

b. Documentation and Training

During reactivation, all documentation should be kept in a central location. This information should serve as the basis for any hazard analysis that may be needed prior to startup. This documentation should address any changes that have occurred during the mothball period. Additionally, all CCD documentation should be reviewed to verify it is correct and current. During the reactivation phase, piping and identification drawings should be field verified to ensure correctness and that all equipment is current.

It should be assumed that a significant portion of the reactivation of a facility will include training. This training can be minimized by having properly performed all documentation during the initial mothball. Reactivating a facility with outdated and incorrect information is unsafe and will most likely result in failure. 
Depending on the duration of the mothball, personnel with experience in operating the existing systems and equipment will be limited. The documentation provided during the preparation and maintenance activities will serve as a guide to train those new individuals on the existing equipment.

\section{F. Electrical}

Mothball considerations for the electrical power distribution system were heavily dependent upon the established requirements imposed by the deactivation and essential mothball maintenance activities chosen for the mechanical, architectural, and structural aspects of the facility. The requirements for reactivation of the facility will be heavily dependent upon the functional needs of the newly reactivated facility.

\section{Lighting and Receptacles}

Exit lighting and emergency egress lighting were not required to remain active in the facility while it was mothballed. These deficiencies should be corrected as part of the reactivation process.

Insulation deterioration of the wiring and ballast deterioration are the two most likely failure modes of the lighting that remained inactive during the mothball period. Depending on whether or not the HVAC systems were active and the success of preventing insect and rodent infiltrations during the mothball period, the lighting covers may need to be cleaned and/or replaced going into the initial portion of the reactivation process. The functionality of the lamps can then be checked and replaced as required.

Another large portion of the lighting infrastructure may have been modified during the deactivation process to simplify the isolation of the electrical system. A thorough study of the planned usage of the reactivated facility versus the available working infrastructure should be conducted to assess the work needed to restore the lighting system to working order.

Make certain that the applicable codes at the time of reactivation do not prohibit the types of lighting previously used in the facility. Task or high bay lighting that is added or restored during the reactivation process that needs to be controlled remotely through the EMCS should be coordinated with the energy management function. Engineering projects or other calculations may need to be completed to bring the facility lighting into compliance.

Insulation deterioration of the wiring and potential moisture and insect/rodent damage are the two most likely failure modes of the receptacles during the mothball period. Entering the initial portion of the reactivation process, the functionality of the receptacles should be checked and replaced as required. Make certain that the applicable codes at the time of reactivation do not prohibit the types of or locations where receptacles are used in the facility. Engineering projects or evaluations may need to be completed to bring the facility into compliance.

\section{Air Cooled Transformers and Substations}

Utilize the information obtained during the deactivation phase for all electrical equipment that was deactivated. Already defined were the types of calibration and testing to be performed with insulation testing included as a high priority during this reactivation phase. Protective relays and circuit breaker cleaning and calibrations should be completed on any equipment that was not active or was altered during the mothball period. The settings for protective devices should be appropriate for the new functionality of the facility and approved as required. Clean any contacts or switches that would be suspect to collecting dust or dirt during the mothball period. A digital low resistance ohmmeter should be used to check these connections.

Any existing problems with equipment that were identified for future evaluation or to be addressed before completing the reactivation process should be remedied at this time. Project designs or partially completed projects that impact the facility electrical system should also be evaluated and executed at this time. Make certain that the applicable codes at the time of reactivation do not prohibit the execution of these projects. Utilize engineering as appropriate to bring these projects into compliance.

Redline configuration controlled drawings to show the revised configuration of the facility. Before the facility has been officially moved back to active status, all existing facility drawings and documents should be moved from the 
"historical archive" section of drawing configuration management system to the "current archive" section and verified to be accurate and/or marked as obsolete. Notify the power distribution computer model administrator (as applicable) to make sure the appropriate electrical equipment status and configuration is reflected in the model.

\section{Oil Filled Transformers}

Oil filled transformers should have remained energized and maintained during the mothball period. Reactivation activities should therefore be limited to a general inspection of the integrity of the transformer (for leaks, animal nests, etc). Maintenance testing such as doble testing and transformer turns ratio testing is not necessary unless it would be advantageous to complete these tests while the facility is not critically operating.

\section{Motors and Generators}

Preparation for service should begin with a thorough cleaning of the motor. Remove any oil, dust or dirt that has accumulated despite precautions taken while preparing the motor for storage. Carefully use low pressure air to blow out the interior of the motor. All desiccant bags should be removed. Condensation drain plugs should be reinstalled and temporary covers removed from all openings. Consider employing the services of outside contractors specializing in such motor rehabilitation work.

For motors with grease-filled bearings stored beyond three years, replace the bearings. For oil-lubricated bearings, drain and fill the lube oil system with approved lubricant prior to re-starting the equipment. Test the motor windings with a megaohm meter in accordance with the motor's rated nameplate voltage and any special manufacturer's instructions. Test the insulation of the feeder wiring to the motor.

\section{UPS and Battery Systems}

If the UPS system was stored in place, a full PM of the UPS should be performed. It may be most useful to contract the manufacturer or a specialty contractor if there is a warranty period left on the UPS. Typically, the batteries were removed, so replacement will be necessary.

\section{Fire Detection Systems}

During the reactivation process, a functional test of the entire fire detection system should be performed. Flow switches, tamper switches, and any other equipment removed or that failed during the deactivation and mothball processes should be replaced as required (see also Section 5.1). Engineering projects or evaluations may need to be completed to successfully accomplish this activity. Pass/fail testing requirements should be defined by the applicable versions of the fire codes in effect at the time of reactivation as well as any supplemental standards established by the fire chief (or equal).

Chemical and atmospheric monitoring systems that are to be connected to the fire control panels should be connected once the monitored process system hazard (oxygen deficiency, combustible concentration of gas, presence of natural gas, etc) has been established inside the reactivated facility. This should be completed prior to the functional test of the fire detection system.

Preventive maintenance programs associated with the fire detection system should be resumed at least one week prior to the facility status changing from inactive to active status.

\section{Environmental Monitoring Systems}

Environmental monitoring systems to be connected to the fire detection system should be completed prior to the functional test of the fire detection system.

Any special instructions included in weather emergency plans while the facility was in mothball status should be formally cancelled once the facility is brought back to active status. 


\section{Security Monitoring and Access Systems}

Coordinate with the Chief of Security to avoid compromising the security of the facility during the reactivation process. Power and communication reactivation activities for any intrusion alarms, controlled access systems, and security cameras should satisfy the security requirements of the reactivated facility. Engineering projects or evaluations may need to be completed to successfully accomplish this activity.

\section{G. Communications}

Because the majority of communications and network systems were likely removed during deactivation of the facility, a thorough functional check of the facility communications backbone should be completed before returning equipment to the facility. Once the equipment is installed, a full functional test of the system should be performed. The performance of the system should be equivalent to or better than the performance noted during deactivation activities. The coordination of this testing and the subsequent return of equipment to the facility should be done at the direction of the communication and network management function.

The relative network position of the mothballed facility for utility metering, network gateways, etc should be evaluated during the reactivation process and adjusted for changes made to other facilities since the mothball process began. Depending upon the configuration of these network systems, there may need to be work performed in other facilities during reactivation to establish normal working communication and network operations at the facility being reactivated.

\section{H. Data Acquisition Systems (DAS) and Facility Automation Systems (FAS)}

The following provides guidance for the development of procedures to reactivate the facility DAS/FAS equipment.

Create a procedure to restore each FAS/DAS systems to working order. This procedure should include references to system drawings, identify deactivation software releases, and explain the sub-systems required to run the main systems.

Identify or create a procedure to demonstrate that the system has been restored to working order. This procedure should also include the calibration of all instrumentation (research/data collection and process related) and the verification of the functionality of mechanical interlock devices. This procedure will likely be a variation of an existing acceptance test plan (ATP). If available, this developed procedure should be executed prior to completion of the deactivation process and those results should be recorded and made available for comparison purposes during reactivation testing. In addition to the execution of ATPs, utilize maintenance and diagnostic tools identified during the deactivation phase to determine the proper operation of the reactivated systems.

Create a report that identifies systems which may be problematic during reactivation. This report should include mitigation strategy with a rough order of magnitude cost (adjusted for the year of the approximated reactivation) and a mitigation schedule. Create a list and procedure to return deactivated DAS equipment to the calibration roster.

Notify organizational computer security officer (or equal) of the reactivation of facility IT assets so that the appropriate status is reflected in the applicable SSP.

Verify and upgrade all computer IT Security software and site security plans to meet the current Center policies and rules in effect at the time of reactivation.

Notify DAS the applicable CM manager of reactivated facility software and refer to baseline software repository as necessary for software restorations. 